\title{
Aspectos da política educacional carioca: trajetórias da Educação Infantil
}

Ana Paula Tatagiba*

\section{Resumo}

0 objetivo do presente trabalho é divulgar a trajetória que as políticas públicas voltadas para a infância de 0 a 6 anos percorreram na cidade do Rio de Janeiro, situando as ações desenvolvidas nas áreas de Educação e Assistência Social. Considerando as repercussões da Lei de Diretrizes e Bases da Educação Nacional vigente desde 1996 são apresentadas análises do contexto contemporâneo, no qual a educação infantil figura como um direito social. Direito este ainda em vias de efetivação já que, apesar da vinculação das creches aos sistemas municipais de ensino, a obrigatoriedade de que os profissionais que atuam diretamente com as crianças nas creches e pré-escolas sejam docentes é um desafio a ser superado.

Palavras-chave: Políticas públicas. Infância. Educação. Assistência social.

\section{Aspects of Rio de Janeiro's educational policies: trajectories of childhood education Abstract}

The objective of this study is to reveal the trajectory of the public policies destined to children from 0 to 6 years old in the city of Rio de Janeiro, situating the actions developed in the areas of Education and Social Assistance.

Considering the repercussion of the Lei de Diretrizes e Bases da Educação Nacional, valid since 1996, analysis of the contemporary context are presented, in which the childhood education is considered a social right. Such right is still to be completely effective for, despite the binding of the daycare centers (crèches) to the municipal educational systems, the obligatorily of the professionals that deal directly with children being educators is a challenge yet to be overcome.

Keywords: Public policies. Childhood. Education. Social assistance.

\footnotetext{
* Mestre em Política Social, Universidade Federal Fluminense (UFF). E-mail: aptatagiba@hotmail.com
} 


\section{Aspectos de la politica educacional de Rio de Janeiro: trayectorias de la Educación Infantil Resumen}

El objetivo del presente trabajo es divulgar la trayectoria de las políticas públicas dirigidas a los niños de 0 a 6 años en la ciudad de Rio de Janeiro, situando las acciones desarrolladas en las áreas de Educación y Asistencia Social. Considerando las repercusiones de la Ley de Directrices y Bases de la Educación Nacional vigente a partir de 1996, es presentado el análisis del contexto contemporáneo en que la educación infantil figura como un derecho social. Derecho este aún en vía de implementación, puesto que, a pesar de la vinculación de las guarderías a los sistemas municipales de enseñanza, la obligatoriedad de que los profesionales que actúan directamente junto a los niños sean profesores es un desafío que hay que superar.

Palabras clave: Políticas públicas. Infancia. Educación. Asistencia social.

\section{Introdução}

Desde 1996, quando a Lei de Diretrizes e Bases da Educação Nacional (LDB) (BRASIL, 1996) foi promulgada, o atendimento à infância ocupa um lugar diferenciado no campo das políticas públicas. A instituição da Educação Infantil' ${ }^{1}$, ocorrida num contexto de descentralização administrativa em que a atuação municipal em diversos setores foi requisitada, suscitou significativas mudanças na estrutura das Prefeituras em todo o Brasil.

Na cidade do Rio de Janeiro, o ano de 2001 marcou a transferência das creches situadas em diferentes comunidades - antes vinculadas à Secretaria Municipal de Desenvolvimento Social (SMDS) ${ }^{2}$ para a Secretaria Municipal de Educação (SME). Tal transferência, que deveria ser realizada até 1999, visou ao atendimento à Lei de Diretrizes e Bases então vigente (BRASIL, 1996).

A considerar-se a abordagem da mídia e o conhecimento da população em relação à temática, poder-se-ia concluir que esse processo reveste-se de pouca importância, estando desvinculado do elenco das requisições que corporificam a cidadania, reclamada por todos. No entanto, nele envolveram-se mais de 4.000 trabalhadores e de, aproximadamente, 39.000 crianças, que passaram a compor o contingente de 754.345 mil alunos que já faziam parte da rede municipal de ensino escolar, a maior da América Latina. ${ }^{3}$

\footnotetext{
A Educação Infantil é uma etapa da Educação Básica, dividindo-se em creche - para crianças de 0 a 3 anos - e pré-escola - 4 a 6 anos - (BRASIL, 1996, art. 30).

2 Desde 6 de maio de 2004, esta Secretaria passou a denominar-se Secretaria Municipal de Assistência Social (SMAS).

3 Informação fornecida pelo Centro de Referência da Educação Pública da Cidade do Rio de Janeiro (2004).
} 
Reconhecendo a importância do atendimento à infância no elenco das políticas públicas, o processo de vinculação das creches à esfera da SME converteu-se em objeto de estudo em pesquisa realizada durante o curso de Mestrado em Política Social, cujos resultados finais foram apresentados ao Programa de Estudos Pós-Graduados da Escola de Serviço Social da Universidade Federal Fluminense, em fevereiro de 2006.

Neste trabalho, compartilha-se com os leitores aspectos estudados durante a realização da referida pesquisa, cujos objetivos foram: caracterizar as políticas sociais destinadas às crianças de 0 a 6 anos, implementadas pelo Estado Brasileiro a partir da década de 70; analisar a vinculação das políticas sociais destinadas ao atendimento do pré-escolar, estabelecendo as inter-relações entre Educação e Assistência Social e; situar historicamente a experiência carioca de Educação Infantil, destacando-se as ações desenvolvidas na modalidade Creche.

Souza (2003, p. 18) pontua que "a análise de políticas públicas é, por definição, estudar o governo em ação" e, independente da etapa do processo de gestação dessas ações em que recaia o interesse de estudo, parece ser sempre uma tarefa desafiadora, já que, além da complexidade da temática, há pouca clareza quanto "sobre quem formula as nossas políticas públicas e como elas são implementadas", somadas à "escassa acumulação do conhecimento na área" (SOUZA, 2003, p. 15).

Em que pese as dificuldades sinalizadas pela autora (SOUZA, 2003), pesquisas documental e bibliográfica, além da realização de entrevistas, possibilitaram a contextualização histórica da emergência e consolidação das ações do Poder Público carioca; assim como a sistematização de dados referentes às experiência recentes desenvolvidas na área.

Celina Souza (2003) expõe também críticas aos modelos de análise de políticas públicas do tipo top-down, centrados nos atores, sugerindo que estas devem ser analisadas a partir das ações de seus implementadores, com a descrição e o estudo das redes de implementação, ressaltando-se a análise do problema que a ação busca resolver (modelo bottom-up).

Consultando a coletânea "Educação Infantil (1983-1996)" (ROCHA; SILVA FILHO; STRENZEL, 2001, p. 10, 12) sobre dissertações e teses acadêmicas que tratam do tema, os autores salientam que "o interior das instituições é pouco investigado", comentando que os "aspectos sociais e históricos presentes nos estudos evidenciaram [...] uma maior preocupação com as políticas", havendo muitos estudos de cunho histórico que apresentam "repetidas sínteses de fatos de uma história recente da educação infantil no Brasil".

Assim é que, com a intenção de garantir espaço e "dar voz" aos educadores das creches públicas - efetivos implementadores da política - , "dando vida" às discussões teóricas e encaminhamentos legais pesquisados, optou-se pela elaboração de 
análise qualitativa. Definiu-se métodos de investigação diferenciados de acordo com cada etapa do trabalho: o estudo de caso, para a estruturação do trabalho como um todo e a análise de conteúdo para se proceder à análise das entrevistas realizadas. Em relação à unidade de análise, pesquisou-se, de janeiro a agosto de 2005, a área de abrangência da $1^{\text {a }}$ Coordenadoria Regional de Educação (CRE) ${ }^{4}$, onde havia 19 creches municipais, que constituíram o universo a ser pesquisado. Ao todo, foram ouvidos 32 educadores.

Dadas as limitações deste artigo, além do retrospecto do atendimento à infância nas áreas de Educação e Assistência Social, são ressaltados os estudos referentes à identidade profissional das educadoras de creche e o desafio enfrentado pelos gestores municipais no cumprimento da exigência legal de que docentes atuem nas creches públicas.

\section{Breve histórico do atendimento à infância de zero a seis anos Políticas implementadas no âmbito educacional}

0 atual município do Rio de Janeiro tem uma história política peculiar: no período de 1892 a 1960 abrigou a sede da República e, além da organização da classe política em nível federal, o cargo de Prefeito compunha seu quadro político-administrativo. Com a inauguração de Brasília, em 21 de abril de 1960, estruturou-se 0 Estado da Guanabara que existiu até 1975, quando houve a Fusão com o Estado do Rio de Janeiro, originando a divisão político-administrativa atual.

Com a fusão, o almirante Faria Lima foi indicado interventor do governo federal no Estado recém criado. Para compor o quadro político da região, Faria Lima indicou Marcos Tamoio para assumir a Prefeitura do município do Rio de Janeiro.

A Secretaria Municipal de Educação e Cultura (SMEC), já em 1975, contava com uma Coordenadoria de Educação Pré-Escolar, que era um órgão de apoio técnico, composto por parte da rede pré-escolar já existente no antigo Estado da Guanabara.

À época, a Prefeitura assumiu o atendimento ao pré-escolar como meta prioritária, adotando a seguinte definição:

Pré-escolar é o termo universal, consagrado pela UNESCO, aceito por congressos e organizações nacionais e internacionais. Ele expressa o que antecede a escola como instituição formal da educação. É, por antítese, a idade do crescimento e do desenvolvimento, não apenas físico, mas so-

${ }^{4} 0$ sistema de ensino carioca está organizado em 10 CREs. A 1 ${ }^{\text {a }}$ CRE é composta pelos seguintes bairros: Bairro de Fátima, Benfica, Caju, Catumbi, Centro, Cidade Nova, Estácio, Gamboa, Mangueira, Paquetá, Praça Mauá, Rio Comprido, Santa Teresa, Santo Cristo, Saúde e São Cristóvão. 
bretudo psíquico, mental e emocional. Pré-escolar é o termo oficial para expressar a faixa etária de crianças de zero a seis anos, independente de se dar ou não atendimento a essas crianças (RIO DE JANEIRO, 1976, não pag.).

Nessa $2^{\text {a }}$ metade dos anos 70, a importância da educação pré-escolar foi referenciada a partir das dificuldades da escola de $1^{\circ} \mathrm{grau}^{5}$. Com o baixo rendimento escolar - expresso pelos altos índices de repetência, notadamente da $1^{\text {a }}$ para a $2^{\text {a }}$ série primária, e pela evasão - gerando congestionamento do sistema e distorções na relação idade da criança-série cursada, buscou-se uma explicação imediata e racionalizada, concluindo-se que:

De fato, a grande maioria das crianças que chega à $1^{\text {a }}$ série da rede oficial, iniciando, assim, sua vida escolar, pertence a lares carenciados. 0 ambiente de onde provém este grupo tão significativo de alunos se caracteriza pela quase total ausência de estímulos sensório-motores, afetivos, sociais e verbais. Por outro lado, condições extremamente precárias de alimentação e saúde acabam por configurar o quadro geral de carência que se torna, desta maneira, fato decisivo de insucesso, agravado pelo fato de, na maioria gritante das vezes, não terem recebido os benefícios de um atendimento pré-escolar anterior em classes maternais e de jardim de infância, já que os sistemas se vêem impelidos, face à obrigatoriedade escolar e à escassez de recursos, de atender adequadamente a crianças antes dos sete anos (RIO DE JANEIRO, 1976, p. 17).

Desta forma, crianças de 4 a 6 anos eram atendidas nas classes de jardim de infância e nas Classes de Alfabetização (CA), criadas desde 1972; destacando-se também a organização de Classes de Adaptação (CAD), para atendimento de alunos de 6 e 7 anos com dificuldades de aprendizagem e a criação dos Centros de Educação Pré-Escolar (CEPEs).

Com esta estrutura de atendimento, os alunos passaram a ser classificados pela Secretaria Municipal de Educação de acordo com sua origem sócio econômica: população rural pobre, favelados, oriundos de orfanato, conjunto residencial pobre, conjunto residencial-favelados e de creche (RIO DE JANEIRO, 1976, p. 33-37).

A creche aparece, assim, pela $1^{\text {a }}$ vez nos levantamentos educacionais, sendo uma instituição referenciada às camadas sociais menos favorecidas.

\footnotetext{
${ }^{5}$ A obra de Sonia Kramer (1987), referência para os estudos em Educação Infantil, apresenta de forma pormenorizada, as origens do ideário, pressupostos e conseqüências da educação compensatória que passou a ser posta em prática.
} 
Em 1977, a Secretaria Municipal de Educação e Cultura divulgou os resultados do I Censo Escolar da cidade do Rio de Janeiro (RIO DE JANEIRO, 1977), atualizando os dados disponíveis desde 1970, data em que o IBGE realizara seu último levantamento.

A coleta de dados, realizada no período de 15 a 22 de setembro de 1975 , mobilizou os vinte Distritos de Educação e Cultura (DECs) que, sob a supervisão das Coordenadorias do Pré-Escolar e do $1^{\circ} \mathrm{grau}$, organizaram-se para que 1.254.949 domicilios fossem visitados. Ao todo, 1.409.624 pessoas foram ouvidas, recenseando-se crianças e jovens com idade entre 2 e 18 anos residentes nas 23 Regiões Administrativas que compunham a estrutura da cidade (RIO DE JANEIRO, 1977, p. 35).

Embora a Secretaria Municipal de Educação tenha elaborado um minucioso trabalho de análise dos dados coletados, a dubiedade de alguns números dificulta sua interpretação. No entanto, partindo de um universo de 849.605 crianças e jovens que formavam a população escolarizada com idade entre 2 e 18 anos, o relatório indica que somente $6,7 \%$ desse total tinha idade de 2 a 6 anos - aproximadamente, 57.000 crianças (RIO DE JANEIRO, 1977, p. 40).

Ao esmiuçar as caracteristicas por Regiões Administrativas e DECs, a faixa etária de 2 e 3 anos de idade é analisada conjuntamente, demonstrando uma unicidade na forma de atendimento e a inexpressividade das oportunidades para acolhimento dessas crianças.

Inexpressividade que, via de regra, marcou o atendimento às crianças de 2 a 5 anos, porque a maioria daqueles que tinham 6 anos completos estavam vinculados à CA - a maioria das crianças no cômputo geral $(55,3 \%)$ e, também, da rede pública $(63,9 \%)$ - já que esta era uma série próxima à etapa de escolarização obrigatória. Neste contexto, os documentos evidenciam que um trabalho para crianças de 0 a 2 anos não era sequer cogitado.

Em 1985, no âmbito do Programa Especial de Educação (PEE) , a rede municipal de ensino passou a ter uma outra forma de atendimento às crianças em idade pré-escolar: em paralelo à construção dos Centros Integrados de Educação Pública (CIEPs), foram criadas as Casas da Criança, como uma forma de atendimento às crianças de 3 a 6 anos.

No documento básico Casa da Criança (RIO DE JANEIRO, 1985, p. 2), em que a proposta para essas instituições é apresentada, verifica-se a manutenção do discurso que marcara os anos 70 ao afirma-se que os objetivos gerais da Casa eram "prestar atendimento à população pré-escolar, de 3 a 6 anos, nas área onde se evidencie o déficit em relação às oportunidades educacionais, nutricionais e de saúde em municípios do Estado do Rio de Janeiro" e "desenvolver um trabalho de investigação e criação pedagógica que atenda às necessidades da comunidade nos seus aspectos culturais, socioeconômicos e de desenvolvimento". 
A proposta das Casas incluía ainda: localização próxima à população de baixa renda, participação ativa da comunidade e funcionamento em horário integral. A participação da comunidade seria efetiva tanto na montagem das $\operatorname{Casas}^{6}$, quanto no desenvolvimento do trabalho educativo, além de envolver a Associação de Moradores na seleção dos agentes educadores.

Os agentes educadores - selecionados entre os moradores da localicade que, preferencialmente, houvessem cursado o $1^{\circ}$ grau (atual Ensino Fundamental) - seriam responsáveis "por toda ação junto às crianças: coordenando os grupos das atividades, preparando e servindo a alimentação, propiciando as condições de higiene pessoal e do ambiente" (RIO DE JANEIRO, 1985, p. 15-16).

Já os professores da rede oficial de ensino seriam indicados "por autoridades educacionais dos órgãos central, regional e locais, escolhidos entre aqueles de reconhecida competência e experiência" e atuariam como parte da equipe dinamizadora ou como professor encarregado. (RIO DE JANEIRO, 1985, p. 18)

Há de se observar que a implementação da proposta das Casas, decorrida uma década de trabalho, recebeu importantes críticas: em 1994, durante o I Simpósio Nacional de Educação Infantil, Rita Cohen Bendetson, que representava a SME no evento, ressaltou que a Secretaria "prestava um atendimento diferenciado às 'crianças do asfalto' e às 'crianças dos nossos morros', dos conjuntos populares e das comunidades" (BENDETSON, 1994, p. 95).

A assessora da SME apresentou uma breve avaliação dessa experiência:

[...] as Casas vieram concretizar o projeto político-partidário do Estado e do Município, que na época privilegiava as instituições de horário integral, assistência alimentar, o acompanhamento médico e a participação ativa da comunidade. Acreditava-se, no interior da SME, que, em nome do saber popular, estas Casas deveriam se manter ao máximo afastadas de qualquer semelhança com a Escola, considerada elitista e distanciada da cultura do povo. As Casas da Criança, durante mais de uma década, receberam todo o investimento e apoio do nível central da SME. Assim, 100 crianças eram em média atendidas em cada Casa em horário integral, por serventes e merendeiras. Sem terem sido concursadas ou

\footnotetext{
${ }^{6}$ Os módulos, feitos de argamassa armada, que compunham a estrutura física dessas instituições eram fabricados na Fábrica de Escolas - inaugurada em $1^{\circ}$ de outubro de 1984 pelo Governo do Estado do Rio de Janeiro para a construção de escolas em série - como os CIEPs - e a baixo custo (se comparado à uma obra convencional). Darcy Ribeiro relata que a Fábrica, fruto do trabalho pioneiro do arquiteto João Filgueiras Lima, tinha potencial na geração de empregos para profissionais de baixa escolaridade , na produção de materiais (cisternas, abrigos de ônibus, escadarias, equipamentos para drenagem, etc.) e na construção de prédios públicos para diferentes áreas, como Educação e Saúde (RIBEIRO, 1986).
} 
contratadas para o trabalho com crianças, sem a formação profissional necessária para isso, sem muitas vezes desejar este tipo de trabalho e, principalmente, desempenhando o papel de professor mas ganhando como um profissional menos qualificado, as serventes e merendeiras lotadas transformaram, com justiça, as Casas da Criança em panelas de pressão social (BENDETSON, 1994, p. 95).

Rita Bendetson (1994) informou também que, após estudos e avaliações realizadas em conjunto por diretores das Casas da Criança e funcionários, professores municipais começaram a ser lotados nessas instituições a partir de setembro de 1993 para que o trabalho pedagógico pudesse, enfim, ser realizado por profissionais qualificados.

Segundo a representante da SME, a lotação dos professores marcou a integração dessas instituições no conjunto de escolas regulares de Educação Infantil que já compunham a rede municipal, "mudança necessária e de difícil execução".7 A partir de então, já não havia mais a obrigatoriedade de funcionamento em horário integral: ser uma instituição de horário parcial ou não passou a ser opcional para cada Casa. (BENDETSON, 1994, p. 95).

\section{Políticas implementadas no âmbito da Assistência}

Segundo o $1^{\circ}$ secretário da Secretaria Municipal de Desenvolvimento Social (SMDS), Marcos Candau, à época de sua estruturação (1979), a Secretaria foi composta por três Coordenações - de Desenvolvimento Comunitário, das Regiões Administrativas e como já "existia uma equipe de Serviço Social, que cuidava das creches. Já tinha uma estrutura montada para isso, [esta] veio integrar a secretaria como [uma 3a] coordenação" (RIO DE JANEIRO, 2004, p. 44).

Um dos fatos mais importantes no início dos anos 80 foi a parceria estabelecida com o Fundo das Nações Unidas para a Infância (UNICEF). Através desta, desenvolveu-se o Programa de Desenvolvimento de Comunidades Urbanas que auxiliou na organização de escolas comunitárias já existentes em algumas favelas e buscou capacitar as crecheiras que já tomavam conta das crianças para que as creches domiciliares fossem ampliadas (RIO DE JANEIRO; UNICEF, 1980, p. 125, 171).

A Coordenação do Bem-Estar Social divulgou, em 1982, que atuava em três frentes através da execução dos seguintes projetos: Guardadeiras Comunitárias, Creches Casulo e Assessoria Técnica às escolas comunitárias.

\footnotetext{
${ }^{7}$ De acordo com a autora, essa integração demandou a consideração das peculiaridades de cada instituição, "estudando caso a caso, a realidade de cada Casa da Criança, seu espaço físico, situação dos funcionários que queriam e dos que não queriam nela permanecer” (BENDETSON, 1994, p. 95).
} 
O nivel da organização das comunidades era considerado um fator determinante para a viabilidade das ações a serem desenvolvidas pela SMDS. Nesse sentido, o projeto Guardadeiras Comunitárias era baseado no trabalho de grupos de mulheres que eram treinadas para cuidar "dos menores em idade pré-escolar enquanto suas mães trabalhavam em atividades externas" (RIO DE JANEIRO, 1982, p. 9).

0 Projeto Casulo, da Legião Brasileira da Assistência, que repercutiu nacionalmente, teve uma atuação significativa também no município do Rio de Janeiro. Através do estabelecimento do primeiro Protocolo entre a LBA e a Prefeitura, deveriam ser implantadas 100 (cem) Creches Casulo. Cada Unidade atenderia a 30 crianças com idades entre 2 e 6 anos, durante 8 horas diárias (RIO DE JANEIRO, [1981?], p. 1).

Com ação extensiva à familia e à comunidade, a creche não deveria limitar-se ao "atendimento direto ao menor", já que todos os que convivem com ele e o grupo do qual faz parte teriam uma participação em seu processo educativo, contribuindo para a satisfação de suas necessidades educativas, recreativas, alimentares, de saúde e vestuário (RIO DE JANEIRO, [1981?], p. 1).

Em 1983, o projeto "Famílias Solidárias" passou a identificar a atuação das Guardadeiras. No entanto, Maria Cristina Martins (1992, p. 56) informa que o mesmo foi renomeado, passando a chamar-se Consolidação e Apoio às Creches Domiciliares em Áreas de Baixa Renda, incorporando profissionais responsáveis pela orientação do trabalho das mães crecheiras moradoras da Rocinha; Vila do Céu, em Santa Cruz; Morro Santa Marta, em Botafogo e Parque Bela Vista, em Honório Gurgel.

Um ano depois, ainda segundo a pesquisadora, entendimentos da SMDS com o UNICEF - que deixou de atuar no município - fizeram com que "as creches domiciliares [fossem] encampadas pela SMDS que as [assumiu] integralmente" (MARTINS, 1992, p. 57).

No parecer de Maria Tereza Goudard Tavares (1998, p. 91), a atuação deste organismo internacional foi associada ao governo Chagas Freitas (1971-1975) e considerada "tecnocrática e afastada dos interesses dos setores populares que a SMDS deveria atender". Além disso, a "preocupação com o conteúdo pedagógico [das escolas comunitárias, um dos pontos trabalhados pelas consultoras do UNICEF] começou a ser vista, por setores da Secretaria, como um afastamento do conteúdo político do trabalho comunitário" (TAVARES, 1998, p. 91).

Em seguida, o trabalho das escolas comunitárias e creches foi unificado, estruturando-se o Programa de Atendimento à Criança (PAC). De acordo com Maria Alice F. Martins (1994, p. 38), em 1992 este deu lugar ao Departamento de Programas de Apoio às Creches e Escolas Comunitárias (DCE). Acontecimentos expressivos nesse período foram o lançamento da Proposta Curricular para 
Creches e Escolas Comunitárias, demarcando a direção pedagógica que essas instituições passaram a assumir; o crescimento acelerado das creches conveniadas e a construção de prédios públicos.

Em 1994, a cidade do Rio de Janeiro vivia os primeiros anos da administração do prefeito César Maia (1993-1997). Após o trabalho de Laura Carneiro à frente da SMDS, sua sucessora Wanda Engel assim resumiu o quadro encontrado na referida Secretaria: "A Secretaria era o programa de creches e os serviços sociais, até porque tinha sido recém-criada a Secretaria de Habitação, e toda a parte de obra, mutirão comunitário, etc, foi para lá" (RIO DE JANEIRO, 2004, p. 197-198).

A participação da sociedade civil colocava-se como condição sine qua non para o desenvolvimento das políticas, e a Secretária informava o que, pelo seu ponto de vista, era um aspecto extremamente positivo:

Todos os programas eram feitos em parceria com ONGs, chegando a mais de 300 convênios. Em todos os níveis. A tentativa sempre foi ter o maior número de ONGs possiveis para evitar monopólios. [...] Quem viesse a se juntar a nós tinha que seguir as orientações básicas da política. Com tudo isso, tivemos uma enorme expansão do atendimento [...]. Quando você descentraliza fica claro quais áreas estão bem servidas ou não de serviços sociais (RIO DE JANEIRO, 2004, p. 199).

Durante a gestão de Wanda Engel foram criados os Centros Municipais de Atendimento Social Integrado (CEMASIS) com o intuito de concretizarem as ações descentralizadas desenvolvidas pela Secretaria Municipal de Desenvolvimento Social, que passara a organizar-se em Coordenadorias Regionais de Desenvolvimento Social (CRs).

Contribuindo para a implementação da política de assistência social, através da integração de programas sociais regionalizados, 47 CEMASIS foram inaugurados, além de 166 CEMASIS Creche ${ }^{8}$. É importante ressaltar que, de acordo com Wanda Engel, quando "se inicia os CEMASIS e a população toma conhecimento, eles passam a ser reivindicação das comunidades do Favela Bairro" (RIO DE JANEIRO, 2004, p. 203).

O Programa Favela Bairro foi elaborado pela Secretaria Municipal de Habitação e seu objetivo era integrar as favelas e os morros ao asfalto, trazendo melhorias para estes locais não apenas do ponto de vista da urbanização com obras de infraestrutura, como também no aspecto social.

\footnotetext{
${ }^{8}$ Em realidade, isso não significa que esse número de instituições foi inaugurado, com prédios novos, pois alguns CEMASIS Creche já funcionavam como instituição vinculada à SMDS tendo apoio integral e funcionando em prédio público. A partir da lei que descentralizou as ações da Secretaria, as creches já existentes passaram a ser identificadas por esta nomenclatura.
} 
Assim, ao lado da rede de creches conveniadas à SMDS - que era composta por creches que recebiam apoio integral ou nutricional ${ }^{9}$, os CEMASIS Creche constituíram-se no lócus da política para a primeira infância, sendo construídos, em algumas localidades, no âmbito do Programa Favela-Bairro.

Todas as creches vinculadas à SMDS passaram a fazer parte do programa Rio Creche e sua organização foi regulamentada, inicialmente, através da Resolução SMDS no 163 (RIO DE JANEIRO, 1994), estruturando-se sob novos critérios a partir de 1998 com a Resolução no 328 (RIO DE JANEIRO, 1998), já na gestão do prefeito Luiz Paulo Conde.

Comparando-se esses dois documentos, há pontos bastante significativos a serem destacados:

- Em relação à população atendida, no final dos anos 90, a SMDS restringiu a faixa etária das crianças, concentrando o trabalho no grupo de 0 a 3 anos. Observando-se a evolução do atendimento prestado às crianças de 4 a 6 anos na SME, infere-se que esta assumiu a responsabilidade pelas crianças dessa faixa de idade.

- Os critérios de elegibilidade presentes nas duas Resoluções consideram o patamar de 2 salários mínimos como uma comprovação de pobreza das famílias; sendo que em 1994 atribuiu-se ênfase ao trabalho feminino para definição dos contemplados com as vagas.

Já em 1998, os critérios alargaram-se, assinalando-se a prioridade dada à criança que vivia em situação de risco social. Assim, a legislação assimilou a idéia de que qualquer atendimento feito à infância deveria ter como referência a própria criança e suas necessidades e não as de sua família, conforme esclarecimento da SMDS:

A promulgação da Constituição de 1988 acarretou algumas modificações no tratamento da questão da Educação Pré-Escolar [...]. A Educação destinada à faixa etária de 0 a 6 anos passa a ser direito da criança e não mais da mãe trabalhadora, ficando sob a responsabilidade do município (RIO DE JANEIRO, 1995, p. 9).

- Em 1994, na composição do quadro de funcionários da creches foi instituída a nomenclatura "agente-bolsista" para designar os trabalhadores que eram remunerados pelas organizações da sociedade civil (OSCs), que estabeleciam convênio com a Prefeitura.

\footnotetext{
${ }^{9} 0$ recebimento de apoio nutricional destinava-se apenas às despesas com alimentação; o apoio integral, incluía, também, o pagamento dos profissionais, despesas com a manutenção da estrutura física, material pedagógico, entre outros.
} 
Devendo morar na comunidade em que a creche estava localizada, esse profissional precisaria ter o $1^{\circ}$ grau completo (atual Ensino Fundamental) para exercer as funções de agente cozinheiro ou agente lactarista; e o $2^{\circ}$ grau completo (atual Ensino Médio) para as funções de agente administrativo e agente educador (para este priorizava-se a formação em magistério). A idade mínima de 18 anos e a experiência anterior em trabalho envolvendo crianças também eram pré-requisitos, além do fato de não poder ser membro da diretoria da entidade que estabeleceria o convênio.

Em 1995, a própria SMDS já avaliava que esses agentes-bolsistas que trabalhavam nas creches ao lado de servidores da Prefeitura, "não [tinham] direitos trabalhistas assegurados, não [tinham] vinculação empregatícia com a Prefeitura, [embora estivessem] subordinados às diretrizes técnicas da Secretaria." (RIO DE JANEIRO, 1995, p. 9). Situação que perdura até os dias atuais, caracterizando o trabalho dos educadores das creches (sejam eles auxiliares de serviços gerais, cozinheiras, lactaristas ou recreadoras); embora o enquadramento como "agente-bolsista" não exista mais.

No que tange aos poucos servidores públicos da SMDS lotados nas creches, é importante que não se perca de vista que estes passaram a exercer suas atividades nos anos 80 , inicialmente, como agentes comunitários. Atendendo à orientação constitucional, estes tornaram-se servidores efetivos da Prefeitura, como explicado a seguir:

Os responsáveis pelo desenvolvimento do Projeto [creches em Centros Comunitários] junto às crianças eram moradores das comunidades, em geral mulheres, contratadas pela Prefeitura como prestadores de serviço. Assim formou-se a categoria de Agentes Comunitários - educadores e merendeiras. 0 critério de seleção para essas funções era o do envolvimento com os trabalhos comunitários e a atuação com as crianças. 0 nivel de escolaridade não era um fator determinante para contratação. [...]

Em 1985 todos os profissionais autônomos foram contratados, pelo regime da CLT, por tempo indeterminado [...], passando a fazer parte do quadro de servidores da Prefeitura. [...]

A promulgação da Constituição de 1988 acarretou algumas modificações no tratamento [...] da contratação de servidores para o Serviço Público. [...] Em relação ao recrutamento de pessoal, o único processo permitido passou a ser o Concurso Público (RIO DE JANEIRO, 1995, p. 8-9).

- A participação da família, no final dos anos 90, extrapolou a participação no Conselho Consultivo da creche - instância composta por representantes de todos os segmentos da instituição (Direção, funcionários, pais e representante da Organização da Sociedade Civil responsável pelo convênio) e que deveria 
acompanhar e avaliar seu funcionamento, sugerindo medidas para a melhoria do trabalho -, passando a incluir o pagamento (em dinheiro ou com trabalho) pelos serviços prestados, em forma de doação.

Essa orientação, apesar de formulada dois anos após a promulgação da LDB vigente, demonstra o quanto a oferta da educação infantil, ainda não era considerada sob a perspectiva do direito social, esperando-se dos pais alguma contrapartida.

No que tange aos aspectos qualitativos, uma caracteristica importante das instituições que fizeram parte da rede direta (localizada em prédios próprios da Prefeitura) e indireta (conveniada) da SMDS era sua destinação/localização: como as Resoluções $n^{\circ} .163$ (RIO DE JANEIRO, 1994) e $n^{\circ} .328$ (RIO DE JANEIRO, 1998) permitem antevê, estas atendiam aos moradores das regiões carentes da cidade estando, em sua maioria, situadas nas favelas cariocas, tendo suas origens baseadas no trabalho comunitário.

Embora este estudo não comporte um debate ampliado sobre as muitas imagens da favela, é extremamente importante que se tenha em mente que as ações públicas implementadas visando ao atendimento em creches na cidade do Rio de Janeiro estão diretamente relacionadas à atuação nestes espaços, sendo esta uma marca definidora das políticas postas em prática nesse campo.

\section{Redesenhando o sistema municipal de ensino}

Com a promulgação da Lei no. 9.394 (BRASIL, 1996), chega-se ao final da década de 90 sob a pressão de um imperativo: vincular todas as instituições de educação infantil, inclusive 0 atendimento prestado às crianças de 0 a 3 anos, ao sistema municipal de ensino.

Um ano antes de ocorrer a transferência das creches da SMDS para a SME, o Conselho Municipal de Educação, através da Deliberação E/CME nº 003 (RIO DE JANEIRO, 2000), fixou as normas para autorização de funcionamento de todas as instituições privadas de Educação Infantil. Essa Deliberação ofereceu os parâmetros para o trabalho voltado para crianças de 0 a 6 anos atendidas em instituições particulares, comunitárias, confessionais e filantrópicas.

No que tange especificamente à vinculação das creches já existentes no âmbito da SMDS ao sistema municipal de ensino, o primeiros passo oficialmente dado em direção ao cumprimento da LDB foi a criação de um Grupo de TrabaIho (GT) para mapear a situação existente na área (RIO DE JANEIRO, 2001d). Em 2001, após concluir este trabalho, o GT apresentou relatório assinalando, entre outros aspectos, que: 
- Havia 468 creches com algum vínculo com a Prefeitura, atendendo a 39.508 crianças na faixa etária de 0 a 3 anos e 11 meses, sob a responsabilidade de um quadro composto por 4060 trabalhadores (468 diretores de creches, 2.642 recreadores, 110 lactaristas, 642 cozinheiras e 407 auxiliares de serviços gerais).

- 92\% dos pais, de acordo com pesquisa realizada pelo Instituto de Pesquisa Econômica e Aplicada - IPEA ${ }^{10}$, estavam satisfeitos com a instituição de educação infantil frequentada por seus filhos;

- era urgente a seleção e capacitação de profissionais da SME para atuarem como supervisores das creches localizadas em prédios públicos. Definiu-se que deveria ser um docente com matrícula única ativa, a fim de que não prejudicasse o exercício de outras atividades. Esses supervisores deveriam iniciar suas atividades em julho de 2001 e seria criado um mecanismo específico que viabilizasse remunerá-los de forma diferenciada.

Entre outras medidas o GT propôs, também, que:

- a SMDS e a SME iniciassem uma gestão compartilhada das creches: em 2001 a SME deveria assumir a supervisão pedagógica das instituições localizadas em prédio público; assumindo integralmente as creches públicas durante o ano de 2002, de forma que, ao final de 2003, as instituições conveniadas (comunitárias, confessionais ou filantrópicas) também já estariam vinculadas à área educacional;

- as recreadoras que trabalhavam nas creches fossem gradativamente substituídas por professores, aceitando-se que, inicialmente, em cada creche houvesse $50 \%$ de profissionais sem formação;

- houvesse a oportunidade para as recreadoras retomarem ou darem continuidade aos seus estudos, fosse através do Programa de Educação Juvenil (PEJ) já implementado nas escolas municipais, fosse através da realização de Ensino Médio nas escolas estaduais, podendo-se contar, por fim, com um curso de complementação pedagógica que poderia ser estruturado através de convênio com a Secretaria do Trabalho, utilizando-se recursos do Fundo de Amparo ao Trabalhador (FAT): ${ }^{11}$

- fosse organizado um Departamento ou Diretoria de Educação Infantil na estrutura do Departamento Geral de Educação (DGE).

\footnotetext{
${ }^{10}$ A origem dessa pesquisa não foi localizada, mas seus dados são referenciados no Relatório do referido GT (RIO DE JANEIRO, 2001a).

${ }^{11} 0$ Fundo de Amparo ao Trabalhador (FAT), criado pela Lei $\mathrm{n}^{\circ}$ 7998, de 11 de janeiro de 1990, é um fundo especial, de natureza contábil-financeira e destina-se ao custeio do Programa do Seguro-Desemprego, do Abono Salarial e ao financiamento de Programas de Desenvolvimento Econômico. A principal fonte de recursos do FAT é composta pelas contribuições para o Programa de Integração Social (PIS) e do Programa de Formação do Patrimônio do Servidor Público (PASEP) (BRASIL, 1990).
} 
Atendendo à orientação do GT que atentava para a premência de elaboração imediata de documento que formalizasse a integração progressiva das creches da SMDS à SME, o prefeito César Maia assinou o Decreto n² 20525, em 14 de setembro de 2001 (RIO DE JANEIRO, 2001c).

Em paralelo, o Conselho Municipal de Educação divulgou a Deliberação $n^{\circ} 06 /$ 2001 (RIO DE JANEIRO, 2001b), fixando normas complementares à Deliberação nº 003 (RIO DE JANEIRO, 2000), cabendo ressaltar os seguintes pontos:

- As instituições comunitárias, confessionais e filantrópicas que já possuíam registro no Conselho Municipal de Direitos da Criança e do Adolescente (CMDCA) deveriam, obrigatoriamente, credenciar-se no Conselho Municipal de Educação; devendo, até o dia 30 de dezembro de 2002 se adequarem à Deliberação 03 (RIO DE JANEIRO, 2000);

- até 31 de dezembro de 2003, as instituições de educação infantil comunitárias, filantrópicas e confessionais poderiam ser dirigidas por professor com formação em Ensino Médio, Decorrido esse prazo, só poderiam ser dirigidas por profissional com formação pedagógica em nível superior.

Essas instituições providenciariam, também, que as recreadoras fossem pouco a pouco substituídas, de forma que, pelo menos $50 \%$ do quadro pudesse ser formado por professores e 50\% estivesse com estudos em andamento visando à formação para o exercício do magistério. Até a data de 31 de dezembro de 2007 todos os profissionais que atuam em creches e pré-escolas deveriam ter como formação mínima o Ensino Médio, na modalidade Normal.

0 cadastramento dos trabalhadores que não possuiam a formação pedagógica seria feito pela SME, que adotaria providências para acompanhamento e controle da formação desses profissionais.

A partir de então, a renovação dos convênios dependeriam do cumprimento desses quesitos. Já as instituições comunitárias, confessionais e filantrópicas conveniadas que não eram ainda registradas no CMDCA ou que, desta data em diante, desejassem estabelecer-se, deveriam enquadrar-se à Deliberação nº 003 (RIO DE JANEIRO, 2000).

\section{Em busca do êxito}

Do elenco de sugestões dadas pelo GT, a primeira medida que, de fato, concretizou a vinculação das creches localizadas em prédio público à SME foi a indicação de professores para realizar a supervisão das creches, feita durante o ano de 2002. Assim, cada professor recebeu um grupo de creches para supervisionar, organizando e acompanhando o processo de planejamento, incluindo-se sua execução e avaliação, e sugerindo atividades. 
Se o trabalho desenvolvido por estes professores já era necessário numa situação que envolvesse docentes, observou-se que tornou-se ainda mais importante pois trabalhava-se num cenário em que o suporte pedagógico deveria ser oferecido às equipes de recreadoras nas quais, teoricamente, encontrar-se-iam profissionais, em sua maioria, sem formação específica.

O Departamento de Educação Infantil foi estruturado, ainda que em caráter oficioso, sem haver um ato administrativo que o criasse e organizasse o seu funcionamento.

Pesquisas realizadas no Diário Oficial do Município do Rio de Janeiro ${ }^{12}$ permitem que se conclua que o limite de 31 de dezembro de 2002 para que as instituições de educação infantil mantidas pela Prefeitura fossem transferidas para a SME não foi cumprido. Assim, os diretores de creche ligados à SMDS foram dispensados, em massa, de sua função, em $1^{\circ}$ de março de 2003 (RIO DE JANEIRO, 2003b); contudo, os primeiros professores indicados pelas CREs para assumiram a direção das creches, só começaram a ser lotados nas respectivas Unidades de Ensino em abril de 2003 (RIO DE JANEIRO, 2003c).

No que se refere à formação das recreadoras, conclui-se que a intenção de compor equipes com 50\% de profissionais com formação em magistério e 50\% de recreadoras em formação não foi alcançada. Até porque, não se encontrou registro de que as três alternativas dadas pelo GT para compensar a formação inadequada de algumas recreadoras fossem incentivadas pela Prefeitura.

Efetivamente, houve o estabelecimento de convênio de uma instituição de ensino superior privada, a Universidade Estácio de Sá (UNESA), com a Fundação Cesgranrio para que, após a aprovação e classificação em concurso Vestibular, educadores de creches ligadas à Prefeitura pudessem graduar-se em Pedagogia. Num primeiro processo seletivo foram oferecidas 1000 vagas.

Excetuando-se esta oportunidade, coube, única e exclusivamente a cada trabaIhador a mobilização para atender às novas exigências referentes à formação escolar na tentativa de, a médio prazo, manter o seu emprego.

Uma das maiores repercussões, no entanto, dos primeiros documentos oficiais foi em relação às instituições comunitárias e filantrópicas que apresentaram dificuldades ao buscar adequação aos novos parâmetros estabelecidos. Dificuldades estas ratificadas pelo Conselho Municipal de Assistência Social que solicitou ao

\footnotetext{
${ }^{12}$ Conforme explicitado no item 1 do presente artigo, a pesquisa documental foi parte importante deste trabalho e a análise das publicações dos Diários Oficiais do Rio de Janeiro (DO) constituiu-se em procedimento fundamental para o acompanhamento das ações implementadas pelo poder público na área da Educação Infantil . No que tange à verificação da implementação das ações sugeridas pelo GT fez-se acompanhamento dos DOs publicados no período de 08 de março de 2001 a 19 de dezembro de 2003.
} 
Conselho Municipal de Educação a extensão do prazo de 30 de dezembro de 2002 para que estas pudessem se enquadrar às exigências da Deliberação nº 003 (RI0 DE JANEIRO, 2000) (notadamente nos aspectos referentes à estrutura física e composição do quadro de pessoal qualificado).

Através do Parecer no 31 (RIO DE JANEIRO, 2002), o CME acentuou que, para que a legislação pudesse ser cumprida por estas instituições, "[fazia-se] necessário um esforço das mesmas e o auxílio do Poder Público com objetivos de não só organizar-se o Sistema Municipal de Ensino como melhorar a qualidade do ensino oferecido à população" (RIO DE JANEIRO, 2002, p. 2); decidindo pela não alteração do prazo já estipulado.

Diante das dificuldades vivenciadas pelas instituições de pequeno e médio porte, a ação mais significativa implementada pela Prefeitura foi a estruturação dos Núcleos de Atendimento à Infância (NACs), ainda no âmbito da SMDS.

Com o objetivo de manter o atendimento oferecido nas instituições que "não atenderam às normas de exigência da Secretaria Municipal de Educação e do Conselho Municipal de Educação" (RIO DE JANEIRO, 2003a, p. 2), os NACs foram criados com a proposta de desenvolver atividades recreativas, culturais e promocionais; considerando-se também

os cuidados relativos a: segurança, higiene, alimentação, recreação, cultura e afeto; inclusive às crianças portadoras de necessidades especiais, devam estar asseguradas através de atividades que proporcionem o desenvolvimento de suas potencialidades. Pelo (sic) convívio entre crianças e adultos e entre as próprias crianças. A proposta apresentada deve implementar ações que possibilitem a integração entre os aspectos físicos, afetivos e sociais para as crianças. (RIO DE JANEIRO, 2003a, p. 2).

Mantendo a forma de convênio, os NACs foram organizados a partir de parceria entre a Prefeitura e outra organização da sociedade civil (Igreja, ONGs, Associações de Moradores, etc.) que se responsabilizava pelo desenvolvimento das atividades.

Ao elencar as atividades necessárias ao funcionamento desses núcleos de atendimento, o planejamento foi pontuado como algo relevante, devendo ser apresentado os objetivos por grupos, de acordo com a faixa etária, bem como o planejamento semanal.

Havia, também, orientações metodológicas, sugerindo-se a inclusão de "trabaIhos em grupo, atividades diversificadas, conversa, debates, dramatizações, entrevistas e excursões" (RIO DE JANEIRO, 2003a, p. 6). 
No que se refere aos recursos humanos, a equipe do NAC seria coordenada por um profissional com "nível superior, completo ou em curso - com experiência em trabalhos comunitários, preferencialmente com crianças". Uma dupla de recreadores deveria ser responsável por cada grupo com vinte crianças e a formação exigida para desempenhar esta função foi "no mínimo ensino médio, preferencialmente com experiência em trabalho com crianças" Para o trabalho com bebês (até 1 ano e 11 meses) exigiu-se o ensino fundamental completo ou em término, com experiência em cuidado com crianças pequenas - cuidados elementares com a rotina das crianças menores (higiene, alimentação e sono)" (RIO DE JANEIRO, 2003a, p. 7).

Ainda que uma análise dos Núcleos de Atendimento à Criança pareça precipitada dado o pouco tempo de existência do projeto e o fato de este ter sido extinto em dezembro de 2005, uma questão ficou bem evidente: o NAC reproduziu a dualidade no sistema municipal, havendo crianças que tiveram o atendimento como preceitua a legislação vigente e outras que foram atendidas de outra forma, distanciada de tais preceitos.

Para cada criança atendida pelo NAC equivalia um repasse de $R \$ 100,00$ (cem reais) - sendo que a maior parte desse valor $(R \$ 85,98)$ era proveniente do orçamento municipal e o valor de $\mathrm{R} \$ 17,02$ era repassado pelo governo federal -. A instituição conveniada deveria utilizar esse valor para arcar com todas as despesas (do pessoal à alimentação), havendo exigências de condições mínimas para que tal convênio com a Prefeitura fosse celebrado, já que a instituição também deveria dispor de meios para oferecer a contrapartida com recursos financeiros provenientes de outras fontes (como doações ou estabelecimento de outras parcerias).

0 fato de os NACs constituírem uma alternativa transitória até que as instituições pudessem adequar-se às exigências legais e o desafio que administradores municipais enfrentaram para não interromper o atendimento à população usuária foram questões que justificaram a existência dessa forma de atendimento.

\section{Análise dos relatos das educadoras de creche}

Serão apresentados abaixo, dados referentes à "identidade do educador" destacados a partir dos relatos dos participantes da pesquisa, cujos objetivos e procedimentos metodológicos estão explicitados no item 1 do presente trabalho. As falas destacadas evidenciam a percepção de muitas educadoras em relação ao seu fazer, colocando em discussão a complementaridade das ações de educação e cuidado característica da educação infantil. 


\section{Relato 1:}

Entrevistador: Em algum momento você pensou em desistir desse emprego?

Educador: Bom, o único momento em que eu pensei em desistir [do trabalho como educadora de creche] foi quando eu vi que não tinha reconhecimento, mas não por parte dos pais. Que eu já tinha percebido que muitas vezes os pais não reconhecem sequer o trabalho dos professores nas escolas, que tão pouco iam levar à sério as recreadoras, ainda que elas sejam educadoras, formadas ou não.

Mas quando eu percebi isso por parte da direção [...] Falavam assim: Não deixem que te chamem de tia, porque você não é irmã do pai ou da mãe. Fale para chamar de professora, de educadora, mas não de tia. Mas na verdade nós não éramos tratadas como professoras ou educadoras. Muitas vezes, vinha uma postura da própria direção que nos tratava como se fôssemos babás ou só recreadoras. (Depoimento de D).

Inicialmente, o desprestígio da carreira do magistério é lembrado pela recreadora que afirma não ter criado a expectativa de ter seu trabalho reconhecido pelos pais. A desvalorização do próprio trabalho por parte da educadora, ainda que, de forma não intencional, reflete o difícil reconhecimento da educação infantil como campo da educação. Os pais, nesse caso, reproduzem concepções que são construidas e legitimadas socialmente.

Oportunizando a reflexão sobre a relação entre o educar e o cuidar com o reconhecimento do educador de creche como profissional, o próximo relato se articula com este primeiro ao evidenciar que "ser colocado apenas como aquele que limpa, que dá o alimento", estritamente ligado às funções vinculadas ao trabalho feminino, socialmente desvalorizadas, são recebidas pela recreadora de forma que a inferioriza.

Esse sentimento de inferiorização fica subentendido também na subalternidade, sugerida pela família, que acaba por reproduzir o lugar social definido para a educação da infância pobre, tendo o fim de demarcar que para realizar as atividades inerentes à educação infantil, notadamente para a faixa etária de 0 a 3 anos, não é necessário o domínio de conhecimentos específicos.

\section{Relato 2:}

Entrevistador: Como é a relação de vocês com a família?

Educador: É complexa porque não podemos agradar a todos. Mas, dentro do possivel, a gente procura manter uma relação amigável com os pais. [...] Tem aqueles pais mais resistentes e até mais ignorantes que acham que a gente quer se meter e que não é função, porque eles não nos vêem como professoras ou educadoras. $A$ 
maioria deles nos vêem como recreadoras ou babás. Já ouvimos isso: Vocês são meras babás, uma vez o pai falou. [...] Eu acho que eles não nos vêem como pessoas que podemos educar os filhos deles para conduzi-los a uma escola, mas alguém que está lá só para cuidar, levar ao banheiro, ajudar na parte de higiene física... [...] Não na questão da educação, de conduzir à escola, de introduzir nesse mundo letrado [...] Acho que eles não vêem por esse lado" (Relato de E).

Nesse contexto, o trabalho desenvolvido na creche é identificado como uma atividade "que qualquer um" pode fazer. Essa forma de pensar foi o que, desde a organização das primeiras organizações comunitárias, marcou o trabalho destinado às crianças de 0 a 6 anos. Hoje, é esse ideário que ainda faz com que a educadora contente-se com um desprestígio que, afinal, segundo a própria entrevistada, é amargado pelos próprios docentes, apesar de estes precisarem de anos de estudo para poderem exercer a profissão.

Sonia Kramer $(2001$, p. 96) recoloca essa questão cultural como uma das tensões da formação do profissional de educação infantil, mencionando a vinculação do trabalho feminino com as atividades de cuidado, interpretado, socialmente, como algo que, para ser executado, "exige pouca qualificação".

Para a pesquisadora,

As atividades do magistério infantil estão associadas ao papel sexual, reprodutivo, desempenhado tradicionalmente pelas mulheres, caracterizando situações que reproduzem o cotidiano, o trabalho doméstico de cuidados e socialização infantil. As tarefas não [eram] remuneradas e têm aspecto afetivo e de obrigação moral. Considera-se que o trabalho do profissional de educação infantil necessita de pouca qualificação e tem menor valor. A ideologia aí presente camufla as precárias condições de trabalho, esvazia o conteúdo profissional da carreira, desmobiliza os profissionais quanto às reivindicações salariais e não os leva a perceber o poder da profissão (KRAMER, 2001, p. 97).

Outro aspecto importante no segundo relato é a noção que a recreadora tem em relação à função social da creche. Quando menciona que "os pais não [as] vêem como pessoas que [podem] educar os filhos deles para conduzi-los a uma escola, [...] [capaz de] as introduzir nesse mundo letrado", remete-se a uma visão de creche que ainda está incrustada no imaginário: a função preparatória para a escola, a possibilidade de compensar carências e garantir um futuro de sucesso na rede escolar. ${ }^{12}$

\footnotetext{
${ }^{12}$ Fúlvia Rosemberg (1984, p. 74) assinala que a creche não é vista como "um local específico tendo um valor próprio". 0 relato da recreadora ratifica, em parte, que esta tem um valor em função do que pode oferecer em relação ao desenvolvimento escolar da criança.
} 
Já a visão de que a creche tem o "potencial de introduzir a criança no mundo letrado", apesar de não explicado pela entrevistada, permite que se entreveja a possibilidade de a creche contribuir para o desenvolvimento cultural da criança, através do acesso a diferentes oportunidades de uso das linguagens, o que, de fato, é um desafio que está posto e ronda as discussões sobre as questões curriculares em relação ao trabalho das instituições de educação infantil.

No $3^{\circ}$ relato, destacado a seguir, outra entrevistada resume o clima vivido durante o processo de vinculação das creches à SME, reiterando as análises anteriormente realizadas:

\section{Relato 3}

Entrevistador: E como você viveu esse processo de sair da SMDS?

Educador: Ah, foi muito estressante [...] Quando houve a troca de diretora, já veio uma pessoa ligada à Educação. Ela foi logo avisando que ia ter um monte de mudança e que não sabia como ia ficar a situação da gente. Ninguém sabia se ia ter concurso ou se a gente ia direto para a Educação [...] Ela até que era uma pessoa que dava pra levar, mas, às vezes, humilhava a gente [...] Ela falava: Vocês estão pensando o quê? Que vão ser professoras de creche? Estão muito enganadas [...] Vão botar professora aqui e vocês vão dar é banho nas crianças [...] Ai, a gente ficou esperando ser mandada embora, pensando que iam chegar as professoras. Ih, foi o maior tumulto na creche! (Relato de T).

\section{0 desafio da formação profissional}

Ao iniciar-se o ano de 2008, além das 1058 escolas municipais, 245 creches públicas já faziam parte do sistema municipal de ensino carioca. Nessas instituições foram atendidas 92.246 crianças de 4 a 6 anos de idade e 28.167 bebês e crianças nas creches. ${ }^{13}$

Esses números, auspiciosamente divulgados pela Secretaria Municipal de Educação, são muito significativos, demonstrando um crescimento das oportunidades de acesso à rede pública, em especial na $1^{\text {a }}$ etapa da Educação Básica. Assim, de acordo com o Departamento de Educação Infantil, se em 1993 havia 19.000 crianças de 4 e 5 anos nas turmas de pré-escola, esse número elevou-se e pode ser melhor dimensionado com a suposição de que é como se, entre 1993 e 2005, 17 novas crianças desta faixa etária chegassem diariamente às escolas.

No entanto, é patente que não basta ampliar a quantidade de vagas, sendo necessário garantir a qualidade do atendimento oferecido. Embora os parâmetros

\footnotetext{
${ }^{13}$ Dados pesquisados no sítio da Secretaria Municipal de Educação (RIO DE JANEIRO, 2008b).
} 
que podem conferir qualidade à educação infantil sejam objeto de amplo debate, entende-se que, minimamente, deve-se atender ao que preceituam as disposições legais no que tange às condições objetivas de trabalho nas pré-escolas e, principalmente, nas creches (incluídas por último no sistema educacional), além das orientações que, sem força de lei, são elaboradas a partir de estudos e pesquisas divulgadas por instituições acadêmicas e pelo próprio Ministério da Educação.

A título de exemplificação, sabe-se que a atuação de profissionais habilitados, responsáveis pelo atendimento integral da criança, desenvolvendo ações de cuidado e educação; do respeito a esses profissionais, expressos, também, pela valorização salarial e pelo investimento em sua formação continuada; da racional e adequada relação entre profissional/criança atendida, possibilitando o estreitamento de laços e a execução das tarefas sem atropelos; da disponibilidade de recursos pedagógicos adequados; da existência de um amplo espaço que oportunize a aprendizagem fora dos marcos da "sala de aula" são alguns requisitos iniciais que devem ser considerados.

No que se refere aos profissionais que atuam nas creches públicas da cidade do Rio de Janeiro, vive-se um momento de transição; já que, com a recente criação do cargo Agente Auxiliar de Creche no Quadro de Pessoal de Apoio à Educação deu-se um segundo passo importante para a estruturação dessas instituições. Esclarece-se que o pontapé inicial desse processo foi a lotação de professores efetivos da SME para os cargos de Diretor(a) e Professor(a) Articulador(a) da creche.

0 acesso ao cargo de Agente auxiliar de Creche dar-se-á através de concurso público de provas ou de provas e títulos, podendo a seleção ocorrer de forma regionalizada, por $C R E^{14}$. Com salário inicial de $\mathrm{R} \$ 461,34,{ }^{15} \mathrm{o}$ agente auxiliar de creche será um profissional com nivel fundamental completo e trabalhará durante 40 horas semanais para realizar, entre outras, as seguintes atribuições (RIO DE JANEIRO, 2007):

- Participar em conjunto com o educador do planejamento, execução e da avaliação das atividades propostas às crianças;

- participar da execução das rotinas diárias, de acordo com a orientação técnica do educador;

- receber e acatar criteriosamente a orientação e as recomendações do educador no trato e atendimento à clientela;

- disponibilizar e preparar os materiais pedagógicos [...]

- responsabilizar-se pela alimentação direta das crianças; e

- cuidar da higiene e do asseio das crianças [...]

\footnotetext{
${ }^{14} 0$ referido concurso foi concluído em fevereiro de 2008. Foram oferecidas 1600 vagas, sendo 81 para pessoas portadoras de necessidades especiais. Cento e dez mil e oito profissionais participaram do processo seletivo (RIO DE JANEIRO, 2008a).

${ }^{15}$ Valor que pode ser ampliado para R\$ 671,10, com acréscimo de auxílio-transporte (RIO DE JANEIRO, 2007).
} 
0 documento não explica quem é o educador que, por repetidas vezes, é posto como referência para o agente auxiliar de creche. Contudo, a separação entre o que é visto como pedagógico e o que não é, por certo, permeou a elaboração do documento.

Desta forma, a disposição da LDB (BRASIL, 1996, art. 62) de que "a formação mínima para o exercício do magistério na educação infantil [...] [é] a oferecida em nível médio, na modalidade Normal" é escamoteada com a divisão de tarefas: o agente auxiliar de creches que cursou, obrigatoriamente, até o Ensino Fundamental não está exercendo o Magistério, ele é só um "Apoio". Quem exercerá o magistério, sem se envolver com atividades que não remetam ao pedagógico - no sentido mais latu do termo -, será o docente que, um dia, chegará às creches públicas cariocas.

No bojo dessa discussão, o pesquisador Kuhlmann Júnior (2001, p. 204) propõe a seguinte questão: "Para as instituições de educação infantil, notadamente a creche, o que significa estar no sistema educacional?"

Em sua visão, há, mais do que uma esperança, um investimento, nesse encaminhamento:

Se a creche passa a fazer parte do sistema educacional do país, ela deixa de ser apresentada como alternativa para pobres incapazes, para ser posta como complementar à ação da família, tornando-se uma instituição legítima e não um simples paliativo. Mas não é por isso que as instituições se tornam educativas, elas sempre o foram e continuarão sendo, aonde quer que estejam. A passagem para o sistema educacional não representa de modo algum a superação dos preconceitos sociais envolvidos na educação da criança pequena (KUHLMANN JÚNIOR, 2001, p. 204).

Campos (1999, p. 113), com muita propriedade, também enfatiza que a inclusão das creches no sistema educacional não garante por si só a superação de uma tradição que sempre considerou esse atendimento como "mal necessário", destinado às famílias pobres; sinalizando que um grande revelador dessa forma de pensar é o currículo adotado nas escolas de formação de professores, que tem ignorado o cuidado como uma nova perspectiva de atuação, reduzindo-o e estigmatizando "qualquer tipo de atendimento que escape do modelo estritamente escolar" que passa a ser considerado como "assistencialista".

Em todo esse contexto, considerando a realidade do sistema público de ensino carioca, percebe-se que as creches - instituições de educação infantil dedicadas às crianças de 0 a 3 anos - não são, ainda, encaradas como instituições educativas como a escola o é, embora desta diferenciem-se significativamente - em que o docente pode vir a exercer suas atividades. A estes, até o presente momento, cabem apenas os postos de direção administrativa e pedagógica da creche. 


\section{Conclusão}

0 debruçar sobre as legislações e os dados coletados durante a pesquisa de campo realizada concorreu para que se conhecesse o processo de vinculação das instituições de educação infantil, na Modalidade Creche, ao sistema público de ensino na cidade do Rio de Janeiro, resgatando-se, através de dados históricos, fatores que até a atualidade influenciam as decisões tomadas pelo poder público nesse campo.

A partir do estudo da vinculação das ações destinadas à criança de 0 a 6 à área assistencial foi possivel observar que a relação estabelecida com as políticas assistenciais (num período em que a própria assistência social não tinha o status atual de política pública, regulamentada por lei específica como se tem a partir de $1988 \mathrm{com}$ a Lei Orgânica da Assistência Social (LOAS) forjou uma forma de atuação caracterizada pela parcimônia na utilização de recursos financeiros, a cooperação entre as partes envolvidas, a precariedade das condições de trabalho, o voluntariado e a não obrigatoriedade de profissionais habilitados para o atendimento à primeira infância.

Tal atendimento era encarado, até a promulgação da Constituição Federal de 88 (BRASIL, 1988), como benemerência e não como direito social. Contudo, a reivindicação à educação infantil como direito das crianças ganhou corpo e concretizou-se a partir de 1996.

A partir de observações e da escuta dos educadores de creche, pode-se concluir que 0 atendimento hoje prestado pelas instituições de educação infantil para crianças de 0 a 3 anos têm uma dupla faceta: ao mesmo tempo em que novas características, vinculadas ao quê fazer cotidiano, foram forjadas; há outras, historicamente predominantes no atendimento às crianças em idade não escolar, que ainda se mantém.

No entanto, as modificações de fundo que embasaram os debates e que, conseqüentemente, originaram as disposições das legislações vigentes, relativas à uma nova visão,em relação à educação das crianças pequenas, carecem ainda de grande investimento, dada a necessidade de construção permanente de sua viabilidade.

Considerando, por fim, a indicação de Mendez (2000, p. 32) ao enfatizar que "o problema da cidadania da infância é hoje a metáfora para discutir o presente e o futuro da cidadania de todos", a expectativa, por ora, é que este trabalho ao divulgar a experiência do Rio de Janeiro, possa contribuir para que, efetivamente, a educação infantil pública consolide-se como um direito social de todas as crianças brasileiras. 


\section{Referências}

BRASIL. Constituição (1988). Constituição da República Federativa do Brasil. Brasília, DF: Senado Federal, 1988.

BRASIL. Lei n 9394, 20 de dezembro de 1996. Estabelece as Diretrizes e Bases da Educação Nacional. Diário Oficial [da] República Federativa do Brasil, Brasília, DF, 23 dez. 1996.

- Ministério do Trabalho e Emprego. Conselho Deliberativo do Fundo de Amparo ao Trabalhador. Fundo de Amparo ao Trabalhador: histórico. Brasília, DF, 1990. Disponivel em: <http://www.mte.gov.br/>. Acesso em: 8 nov. 2005.

BENDETSON, R. C. Limites e horizontes da educação infantil no Município do Rio de Janeiro. In: SIMPÓSIO NACIONAL DE EDUCAÇÃO INFANTIL, 1., 1994, Brasília. Anais... Brasília, DF: MEC, 1994.

CAMPOS, M. M. A mulher, a criança e seus direitos. Cadernos de Pesquisa, São Paulo, n. 106, p. 117-128, mar. 1999.

KRAMER, S. Formação de profissionais de educação infantil: questões e tensões. In: KRAMER, S. et al. Formação de profissionais da educação infantil no Estado do Rio de Janeiro: relatório de pesquisa. Rio de Janeiro: Ravil, 2001.

KRAMER, S. A Política pré-escolar no Brasil: a arte do disfarce. 3. ed. Rio de Janeiro: Dois Pontos, 1987.

KUHLMANN JÚNIOR, M. Infância e educação infantil: uma abordagem histórica. 2. ed. Porto Alegre: Mediação, 2001.

MARTINS, M. A. F. Escolas comunitárias: o processo de absorção pelo município do Rio de Janeiro. 1994. 92 f. Dissertação (Mestrado em Educação) - Instituto de Estudos Avançados em Educação, Fundação Getúlio Vargas, Rio de Janeiro. 1994.

MARTINS, M. C. As escolas e creches comunitárias nas favelas do Rio: uma história de "correr atrás" da escola contra o jogo do "é pegar ou largar". 1992. 118 f. Dissertação (Mestrado em Educação) - Universidade Federal Fluminense, Niterói, RJ, 1992.

MENDEZ, E. G. Cidadania da criança: a Revolução Francesa com 200 anos de atraso. Revista Inscrita, Rio de Janeiro, ano 1, p. 24-32, nov. 1997. 
RIBEIRO, D. O livro dos CIEPs. Rio de Janeiro: Bloch, 1986.

RIO DE JANEIRO (Estado). Secretaria de Educação. Programa Especial de Educação: documento básico: Casa da Criança. Rio de Janeiro, 1985. Mimeografado.

RIO DE JANEIRO (RJ). Secretaria Municipal de Administração. Educação, saúde e bem-estar social: as prioridades da administração Júlio Coutinho. Rio de Janeiro: Imprensa Oficial, Departamento Geral, [1981?].

. Secretaria Municipal de Assistência Social. Memória da assistência social carioca: história oral. Rio de Janeiro, 2004.

. Secretaria Municipal de Educação e Cultura. Atendimento ao pré-escolar do Município do Rio de Janeiro. Niterói: Imprensa Oficial do Estado do Rio de Janeiro, 1976.

. Secretaria Municipal de Educação e Cultura. I Censo Escolar. Niterói: Imprensa Oficial do Estado do Rio de Janeiro, 1977.

. Secretaria Municipal de Desenvolvimento Social. Estudo de gerenciamento de creches. Rio de Janeiro, 1995.

. Secretaria Municipal de Desenvolvimento Social. O que é a SMD?. Rio de Janeiro: Secretaria Municipal de Administração, Departamento Geral de Imprensa Oficial. 1982.

. Secretaria Municipal de Desenvolvimento Social. Núcleo da Infância e Adolescência. Diretrizes para implantação do Núcleo de Atendimento à Criança (NAC). Rio de Janeiro, dez. 2003a. Mimeografado.

Secretaria Municipal de Desenvolvimento Social. Secretaria Municipal de Educação. Relatório do Grupo de Trabalho. Rio de Janeiro, 2001a. Mimeografado.

. Secretaria Municipal de Desenvolvimento Social; UNICEF. Propostas para ação nas favelas cariocas. 2. ed. Rio de Janeiro, 1980. Mimeografado.

. Centro de Referência da Educação Pública. Escolas tombadas. Rio de Janeiro, 2004. Disponivel em:

<http://www.rio.rj.gov.br/sme/crep/esc_tom.htm>. Acesso em: 19 jun. 2004. 
RIO DE JANEIRO (RJ). Conselho Municipal de Educação. Deliberação E/CME no 003, de 9 de agosto de 2000. Fixa normas para autorização de funcionamento de instituições privadas de Educação Infantil, no Sistema de Ensino do Municipal do Rio de Janeiro e dá outras providências. Diário Oficial do Município do Rio de Janeiro, Rio de Janeiro, RJ, ano 14, n. 197, p. 77-80, 29 dez. 2000.

. Conselho Municipal de Educação. Deliberação E/CME nº 06, de 25 de set. de 2001. Fixa normas complementares à Deliberação E/CME № 03/2000 e dá outras providências. Diário Oficial do Município do Rio de Janeiro, Rio de Janeiro, RJ ano 15, n. 138, p. 20-21, 2 out. 2001 b.

. Conselho Municipal de Educação. Parecer n 31, de 05 de set. de 2002. Responde à consulta do CMAS sobre dilatação de prazo para Credenciamento de Instituição de Educação Infantil. Parecer, Rio de Janeiro, 2002. Disponível em:<http://www. rio.rj.gov.br/sme>. Acesso em: 1 abr. 2005.

. Fundação João Goulart. Informações sobre concurso público de agente auxiliar de creche. Rio de Janeiro, 2008a. Disponivel em:<http:// www.rio.rj.gov.br/sme/>. Acesso em: 21 jan. 2008.

. Prefeitura. Decreto n ${ }^{\circ} 20.525$, de 14 de setembro de 2001. Transfere o atendimento de educação infantil da Secretaria Municipal de Desenvolvimento Social para a Secretaria Municipal de Educação. Diário Oficial do Município do Rio de Janeiro, Rio de Janeiro, RJ, ano 15, n. 127, p. 3, 17 set. 2001c.

Prefeitura. Edital Conjunto SME/SMA n 08, de 24 de julho de 2007. Regulamenta o concurso público para provimento no cargo de Agente Auxiliar de Creche do Quadro Permanente de Pessoal do Poder Executivo do Município do Rio de Janeiro, no âmbito da Secretaria Municipal de Educação. Diário Oficial do Município do Rio de Janeiro, Rio de Janeiro, RJ, ano 21, n. 88, 25 jul. 2007. Disponivel em: <http://doweb.rio.rj.gov.br/sdcgibin/ om_isapi.dll?Ctsoftpage=_infomainCtinfobase=25072007.nfo>.

Acesso em: 5 dez. 2007.

. Prefeitura. Lei $n^{\circ}$ 2.459, de 5 de agosto de 1996. Dispõe sobre a descentralização das ações de Desenvolvimento Social e a criação dos Centros Municipais de Atendimento Social Integrado, na Secretaria Municipal de Desenvolvimento Social, e dá outras providências. Diário Oficial do Município do Rio de Janeiro, Rio de Janeiro, RJ, ano 10, n. 102, p. 2, 9 ago. 1996.

. Prefeitura. Resolução "P" no 364, de 2 de março de 2001. Cria Grupo de Trabalho para os fins que menciona e dá outras providências. Diário Oficial do Município do Rio de Janeiro, Rio de Janeiro, ano 14, n. 243, 7 mar. 2001d. 
RIO DE JANEIRO (RJ). Prefeitura. Resoluções "P", de 28 de fevereiro de 2003. Diário Oficial do Município do Rio de Janeiro, Rio de Janeiro, RJ, ano 16, n. 238, p. 25-29, 11 mar. 2003b.

. Prefeitura. Resoluções "P", de 31 de março de 2003. Diário Oficial do Município do Rio de Janeiro, Rio de Janeiro, RJ, ano 17, n. 14, p. 15-16, 03 abr. 2003c.

. Prefeitura. Resolução SMDS no 163, de 12 de agosto de 1994. Fixa critérios e normas para o funcionamento das creches e pré-escolas da Secretaria Municipal de Desenvolvimento Social. Diário Oficial do Município do Rio de Janeiro, Rio de Janeiro, RJ, ano 8, n. 106, p. 15-17, 16 ago. 1994.

. Prefeitura. Resolução SMDS no 328, de 18 de dezembro de 1998. Fixa critérios e normas para o funcionamento das creches da Secretaria Municipal de Desenvolvimento Social, em substituição à Resolução no 163 de 12 de agosto de 1994 e dá outras providências. Diário Oficial do Município do Rio de Janeiro, Rio de Janeiro, RJ, ano 12, n. 192, p. 13-14, 21 dez. 1998.

. Secretaria Municipal de Educação. Educação, Rio de Janeiro, $2008 \mathrm{~b}$. Disponivel em: <http://www.rio.rj.gov.br/ >. Acesso em: 13 fev. 2008.

ROCHA, E. A. C.; SILVA FILHO, J. J.; STRENZEL, G. R. (Org.). Educação Infantil (1983-1996). Brasilia, DF: MEC, Inep, Comped, 2001. (Estado do Conhecimento; n. 2). Disponivel em: <http://www. publicacoes.inep.gov.br/.../serie_doc_educacao_infantil_164.pdfs. Acesso em: 25 jun. 2008.

ROSEMBERG, F. 0 movimento de mulheres e a abertura política no Brasil: o caso da creche. Cadernos de Pesquisa, São Paulo, n. 51, p. 73-79, nov. 1984.

SOUZA, C. "Estado do campo" da pesquisa em políticas públicas no Brasil. Revista Brasileira de Ciências Sociais, São Paulo, v.18, n. 51, p.15-20, fev. 2003.

TAVARES, M. T. G. A visibilidade que (quase) ninguém vê: a relação entre etnia, pobreza e exclusão na trajetória das creches comunitárias nas favelas cariocas. Cadernos Cedes, Campinas, SP, n. 38, p. 84-99, ago. 1998.

Recebido em: 07/05/2008

Aceito para publicação em: 20/10/2009 